\title{
O desempenho de grandes empresas do BRIC, EUA, Japão e Alemanha: uma comparação com base na geração de valor
}

\section{Performance of large companies of BRIC, USA, Japan and Germany: a comparison based on value creation}

\author{
Tomaz Alvarez Ciani ${ }^{1,2}$ \\ Tabajara Pimenta Junior ${ }^{1,3}$ \\ Rossimar Laura de Oliveira ${ }^{4}$
}

\begin{abstract}
Resumo: Este trabalho buscou responder à questão: empresas atuantes em países desenvolvidos são mais capazes de gerar riqueza do que aquelas presentes nos países emergentes? Para este fim, foi desenvolvida uma pesquisa quantitativa, com o uso de ferramentas estatísticas, para analisar comparativamente os níveis de geração de valor econômico (EVA - Economic Value Added) de um conjunto específico de empresas dos países do BRIC e de três países desenvolvidos (EUA, Japão e Alemanha). Foram coletados dados das principais empresas de capital aberto de cada país, referentes ao período de 2000 a 2010. Os resultados mostraram que, em média, as empresas de ambos os grupos de países são agregadoras de valor. Mostraram também que as empresas dos EUA são, destacadamente, mais geradoras de valor que as empresas de qualquer um dos demais países. Foram obtidos dois resultados inovadores, em relação ao estabelecido na literatura: a detecção de que empresas de ambos os grupos de países obtiveram o mesmo nível de retorno sobre o capital investido; e a constatação de que as empresas da maioria dos países emergentes do BRIC são agregadoras de valor, o que não ocorreu com os países desenvolvidos.
\end{abstract}

Palavras-chave: Valor econômico; EVA; BRIC; Gestão organizacional.

\begin{abstract}
This study aimed to answer the question: Are companies operating in developed countries able to generate more wealth than those present in emerging countries? To this end, we developed a quantitative research using statistical tools to comparatively analyze the levels of generation of economic value added (EVA - Economic Value Added) of a specific set of companies from the BRIC countries and three developed countries. Data from major public companies in each country were collected for the 2000-2010 period. The results showed that, on average, companies in both groups of countries are value adding. They also showed that U.S. companies notably create more value than companies of any of the other countries studied. Two innovative results were obtained in relation to the established literature: detection that companies from both groups of countries achieved the same level of return on invested capital; and detection that the majority of companies from the BRIC countries are value adding, which did not occur with the companies of developed countries.
\end{abstract}

Keywords: Economic value; EVA; BRIC; Company management.

\section{Introdução}

Empresas atuantes em países desenvolvidos são mais capazes de gerar riqueza do que aquelas presentes nos países emergentes?

A geração de valor econômico por uma empresa ocorre quando o retorno obtido com a aplicação do capital nela investido supera o custo deste capital.

\footnotetext{
${ }^{1}$ Group for Research and Teaching in Finance - GRT Finance, Av. Bandeirantes, 3900, CEP 14040-905, Ribeirão Preto, SP, Brasil, e-mail: tomazciani@yahoo.com.br

${ }^{2}$ Faculdade de Economia, Administração e Contabilidade de Ribeirão Preto, Universidade de São Paulo - USP, Av. Bandeirantes, 3900, CEP 14040-905, Ribeirão Preto, SP, Brasil

${ }^{3}$ Departamento de Administração, Faculdade de Economia, Administração e Contabilidade de Ribeirão Preto, Universidade de São Paulo - USP, Av. Bandeirantes, 3900, CEP 14040-905, Ribeirão Preto, SP, Brasil, e-mail: taba.jr@usp.br

${ }^{4}$ Centro Universitário UNISEB Interativo, R. Abraão Issa Halack, 980, CEP 14096-160, Ribeirão Preto, SP, Brasil, e-mail: rossimarlaura@yahoo.com.br
} 
Este valor econômico gerado é chamado de EVAEconomic Value Added - denominação no idioma inglês que, em português, significa Valor Econômico Adicionado ou seja, o EVAé obtido quando o resultado operacional líquido, inclusive dos impostos, é mais do que suficiente para remunerar os financiadores da empresa, credores e proprietários. $\mathrm{O}$ conceito de EVA é mencionado na literatura financeira, sem uma definição propriamente dita, desde o século 18, mas foi Stewart (1991) quem teve o mérito de ter estabelecido e difundido o conceito, tendo inclusive patenteado a sigla EVA.

$\mathrm{O} E V A$ é uma métrica de desempenho que possibilita a mensuração do valor da empresa e é considerada, conforme afirmam Ivanov et al. (2014), muito importante para a gestão estratégica. Trata-se de uma forma de mensuração de desempenho que se revela muito útil e aplicável na medida em que, de acordo com Dunbar (2013), permite identificar o nível de riqueza gerada por diferentes dimensões de unidades de negócios, de um projeto a uma corporação. $\mathrm{O} E V A$ pode ainda alinhar os objetivos da gestão com os dos acionistas, já que sua adoção como medida de desempenho, como esclarece Sirbu (2012), tende a melhorar a prestação de contas e tornar mais evidente o foco na geração de riqueza.

Nos diversos países do mundo, o EVA se consolidou como uma medida de interesse de investidores e gestores, por ser confiável para revelar a qualidade do desempenho econômico das empresas e servir de ponto de referência na definição de estratégias. Segundo Rappaport (2001, p. 82), “[...] a atratividade de um setor também será afetada pelo nível de investimentos em recursos, e capacidade, necessários para manter seu potencial de criação de valor." Por razões como esta, além da capacidade de descrever a verdadeira rentabilidade da empresa, a metodologia do EVA é utilizada por grandes corporações, como apontam Mamun et al. (2012).

Ehrbar (1999), há mais de uma década, já mostrava a ampla aceitação do $E V A$ na comunidade acadêmica e na mídia especializada em investimentos, especialmente junto aos analistas de Wall Street. Grandes empresas e instituições financeiras americanas adotaram formalmente o EVA como direcionador principal na avaliação do desempenho organizacional, assim como outras instituições da Europa, Ásia e América Latina, aguçando o olhar dos investidores para esta nova tendência. Por isso, as empresas, principalmente as de capital aberto, ainda que não tivessem interesse em utilizar o EVA como uma medida interna de desempenho, acabaram por monitorá-lo, sabendo que muitos investidores o consideram em suas decisões de investimento.

Se o EVA é uma medida de geração de riqueza, de agregação de valor ao capital investido, é de se esperar que as empresas de países mais ricos sejam mais competentes nesse processo do que aquelas constituídas nos países menos ricos ou mesmo nos mais pobres. Esta expectativa surge da relação simples entre empresas gerando riqueza e, por consequência, tornando a economia e a sociedade do país mais rica. Por este raciocínio, a riqueza econômica de um país viria, em grande parte, da geração de riqueza proporcionada pelas empresas nele estabelecidas. Contudo, há controvérsias sobre esta ideia. De outro lado, há o raciocínio de que nos países mais ricos, com economias mais sólidas e organizadas, as oportunidades de agregação de valor tendem a desaparecer. Nas economias mais maduras, o capital investido é remunerado adequadamente pelo risco a que se expõe. Há maior equilíbrio. A agregação de valor representa uma remuneração em excesso e requer, portanto, uma oportunidade excepcional, certo desequilíbrio de mercado, uma determinada vantagem competitiva. Este tipo de vantagem pode estar mais facilmente presente nas economias emergentes e, como consequência, há a possibilidade de que as empresas neles localizadas sejam geradoras de maiores quantidades de valor econômico.

Um estudo pioneiro sobre a relação entre a geração de valor pelas empresas e as economias dos países foi o de Copeland et al. (2000), que trouxe à luz o fato em que as economias cujas empresas eram administradas com foco na geração de valor econômico para enriquecimento dos acionistas tinham melhor desempenho do que aquelas cuja filosofia de gestão abrangia outras preocupações (ambientais, sociais, aprendizado etc.) além dos interesses dos proprietários. O estudo feito pelo Mckinsey Global Institute verificou que o PIB per capita dos EUA foi maior do que o do Japão e da Alemanha, no período de 1974 a 1993, e que esta diferença se deu principalmente pela disparidade dos retornos financeiros das empresas destes países. Os gestores das companhias norte-americanas, mais focados no enriquecimento dos acionistas, obtiveram retornos sobre o capital investido em patamares médios anuais de $9,1 \%$, enquanto os das empresas alemãs alcançaram 7,4\% e os das empresas japonesas obtiveram retornos médios anuais de $7,1 \%$. O estudo mostrou que os recursos aplicados em corporações dos EUA agregaram mais valor que aqueles aplicados em empresas no Japão ou na Alemanha, o que afetou o resultado do indicador PIB per capita.

A perspectiva da geração de valor pode ser fundamental para atrair investidores para um país. Dentre os países alvos dos investidores internacionais, um grupo vem recebendo destaque no cenário mundial, o BRIC. O termo foi criado pelo economista O'Neill (2001), chefe de pesquisa em economia global do grupo financeiro Goldman Sachs, em referência, 
na ocasião, a quatro países: Brasil, Rússia, Índia e China. Mais recentemente, em 2011, a África do Sul passou a compor o grupo e o acrônimo passou a ter um "S" a mais (do inglês South Africa), tornando-se BRICS. Como este estudo investiga um período anterior ao ingresso da África do Sul ao grupo, os dados referem-se aos quatro países originais.

Os países do BRIC têm o PIB mais representativo dentre as economias emergentes em todo o mundo. Especula-se que este grupo de países pode se tornar a grande força da economia mundial, superando o grupo das principais potências econômicas que formam o atual G-6 (Estados Unidos, Japão, Alemanha, Reino Unido, França e Itália), em termos de crescimento do PIB, renda per capita e movimentos comerciais e financeiros.

A ascensão do BRIC no cenário econômico global e a importância da geração de valor pelas empresas, como fator de atração de investimentos e de desenvolvimento econômico e social dos países em que se inserem, foram aspectos que suscitaram a seguinte questão de pesquisa: Quais empresas geram mais valor econômico: aquelas atuantes nos países desenvolvidos ou as atuantes nos países emergentes do BRIC?

Em consonância com a questão estabelecida, este trabalho tem o objetivo de comparar o desempenho, medido pela geração de valor econômico, das empresas de três dos principais países desenvolvidos do mundo com o das empresas presentes nos países emergentes do BRIC.

\section{A gestão com base em geração de valor}

De acordo com Ehrbar (1999), a gênese teórica do EVA é encontrada no modelo econômico do valor da empresa proposto por Modigliani \& Miller (1958, 1959, 1963). A partir destes trabalhos, Stewart (1991) estruturou um sistema gerencial de fácil compreensão, baseado na geração de valor, e que atendia à demanda empresarial por medidas de desempenho mais eficazes. O EVA funciona como um sistema de gestão financeira e de remuneração variável pelo desempenho. Ele envolve todo o processo de tomada de decisão organizacional, do nível estratégico ao operacional, bem como a integração entre financeiro e estratégico (Ehrbar, 1999), possibilitando que as pessoas da organização trabalhem com os mesmos conceitos, procedimentos e objetivos.

Uma empresa consegue gerar EVA quando o resultado obtido com suas operações, depois de considerados os custos, despesas e impostos, é suficiente para remunerar adequadamente os recursos de terceiros e de proprietários que compõem o capital investido no negócio.
Segundo Rappaport (2001), as empresas que conseguem agregar valor a partir das decisões tomadas têm maiores chances de sobrevivência. Empresas com a visão voltada para a gestão do valor têm um entendimento melhor da concepção dos negócios e a continuidade do empreendimento. O investimento na empresa somente será atrativo quando a remuneração oferecida for suficiente para compensar o custo de oportunidade do capital e os riscos incorridos. Se uma empresa remunerar seus investidores apenas o suficiente para suprir suas expectativas mínimas de retorno, não haverá qualquer valor agregado ao capital, e suas ações deverão refletir tão somente o valor dos seus ativos.

Os gestores devem ter consciência das vantagens competitivas de suas organizações, bem como preservá-las, garantindo a sua sustentabilidade. A estimativa do potencial gerador de valor das estratégias de uma empresa, no longo prazo, influenciará, ainda segundo Rappaport (2001), diretamente a ausência ou presença da vantagem competitiva. Para tanto, a geração de valor deve ser o foco, e a gestão estratégica, conduzida de forma a detectar ou gerar alternativas de investimento de longo prazo capazes de proporcionar um ganho excedente ao custo do capital utilizado.

As estratégias e objetivos estruturados na empresa devem dirigi-la para a criação de valor, focando os esforços de seus colaboradores na geração futura de excedentes de remuneração do capital. Isto significa que as estratégias definidas e executadas com as atividades cotidianas devem impactar diretamente o valor da empresa. Este processo de planejamento e execução das estratégias afeta todos os níveis da hierarquia, e requer uma cultura que permeie toda a organização. Uma vez instalada uma cultura favorável à criação de valor, a empresa pode estruturar um sistema de Gestão Baseada em Valor (GBV).

A GBV é definida na obra seminal de Copeland et al. (2000, p. 86) como “[...] uma abordagem administrativa segundo a qual as aspirações da empresa, suas técnicas analíticas e seus processos gerenciais são alinhados para ajudá-la a maximizar seu valor.” Ehrbar (1999) coloca a GBV como uma estrutura para configurar um sistema de administração financeira com eficiência, porque é capaz de fornecer direcionadores de valor que contribuem na análise das decisões de financiamentos, investimentos, receitas, custos e despesas. E ainda aponta três objetivos-chave de um sistema de remuneração alinhado com o conceito de valor: (a) o alinhamento dos interesses dos gestores e dos acionistas; (b) a alavancagem, verificada através da variabilidade das recompensas potenciais; (c) e a redução do risco de profissionais valorizados deixarem a organização.

Além do conceito e dos objetivos fundamentais da GBV, é imprescindível a utilização de uma 
métrica capaz de apurar o nível de valor gerado ou destruído. Copeland et al. (2000) ressaltam ainda que é fundamental para uma companhia ter métrica quantitativa que forneça à empresa informações de seu desempenho e evolução na busca de um sistema orientado para o valor.

As informações contábeis não devem ser utilizadas para analisar a criação de valor, pois não levam em conta as medidas de risco financeiro e do negócio, nem a necessidade de capital de giro e o investimento em ativos permanentes que suportariam o crescimento previsto. Assim, segundo Rappaport (2001), não se pode relacionar os lucros ou prejuízos ao nível de geração de valor de determinada empresa.

Dado que as informações contábeis não têm a finalidade de apurar a geração de valor de uma organização, uma vez que não levam em conta as medidas de risco financeiro e do negócio, nem a necessidade de capital de giro e o investimento em ativos permanentes que suportariam o crescimento previsto, é clara a necessidade de outras métricas de desempenho alinhadas com as prerrogativas da Gestão Baseada em Valor. Entre as métricas criadas para suprir esta demanda está a mais efetiva delas, o EVA.

\section{Metodologia}

Este estudo teve o caráter exploratório, na medida em que não pretendeu confirmar uma determinada hipótese, mas obter resultados quantitativos que pudessem ilustrá-la com base numa amostra representativa.

Para comparar o desempenho das empresas em relação à geração de valor, foram coletadas informações financeiras de um conjunto específico de companhias listadas nas bolsas de valores dos países do BRIC (Brasil, Rússia, Índia e China) e de três países desenvolvidos (EUA, Japão e Alemanha). Os dados analisados são referentes a um período de onze anos entre 2000 e 2010, e foram obtidos no sistema de informações Thomson Reuters. O intervalo de tempo considerado tem seu extremo inicial no período pós-crises de 1997 (Crise Asiática) e 1998 (Crise Russa), e seu extremo final no período pós-crise de 2008 (Crise do Sub-Prime). A análise com dados deste período pode ser representativa para considerações sobre um futuro intervalo de tempo entre grandes crises financeiras com início na recente crise de 2008.

As companhias escolhidas para constituir a amostra, cujos nomes constam no Quadro 1, foram as 15 que tiveram o maior volume financeiro negociado nas bolsas de seus países, ao longo do período considerado. O critério de seleção das empresas baseado no volume de negociação de suas ações foi escolhido por indicar aquelas capazes de atrair maior volume de investidores e/ou de capitais.
O Valor Econômico Adicionado (EVA) foi calculado pela Equação 1:

$$
E V A=(R O I C-W A C C) * I C
$$

Em que:

EVA: Valor Econômico Adicionado (Economic Value Added);

ROIC: Retorno sobre o capital investido (Returno On Invested Capital);

WACC: Custo médio ponderado do capital (Weighted Average Cost of Capital);

IC: Capital investido (Invested Capital).

O ROIC foi calculado com a Equação 2:

$$
R O I C=N O P A T / I C
$$

Em que:

ROIC: Retorno sobre o capital investido (Returno On Invested Capital);

NOPAT: Lucro Operacional Tributado (Net Operating Profit After Taxes);

IC: Capital investido (Invested Capital).

Foi considerado capital investido todo capital alocado em ativos operacionais e que exige remuneração financeira explícita, conforme estabelecido por Stewart (1991).

O WACC foi calculado com a Equação 3:

$$
W A C C=R_{e} x \frac{E}{E+D}+R_{d} x \frac{D}{E+D} x(1-T)
$$

Em que:

$\mathrm{R}_{\mathrm{e}}$ : Taxa que representa o custo do capital próprio; $\mathrm{R}_{\mathrm{d}}$ : Taxa que representa o custo do capital de terceiros; E: Capital próprio (Equity);

D: Capital oneroso de terceiros (Debt);

T: Alíquota do Imposto de Renda (Taxes).

O custo do capital próprio foi estimado pelo Modelo de Precificação de Ativos de Capital (CAPM - Capital Asset Pricing Model), proposto por Sharpe (1964), e adaptado por Assaf (2003) para aplicação em mercados externos aos EUA. A expressão do modelo adaptado, que considera o ajuste pelo risco-país em relação aos EUA, é dada pela Equação 4:

$$
R_{e}=R_{F}+\beta^{*}\left(R_{M}-R_{F}\right)+\alpha
$$

Em que:

$\mathrm{R}_{\mathrm{e}}$ : Taxa que representa o custo do capital próprio;

$\mathrm{R}_{\mathrm{F}}$ : Taxa livre de risco da economia dos EUA;

$\mathrm{R}_{\mathrm{M}}$ : Taxa de retorno do mercado dos EUA;

$\beta$ : Coeficiente beta de risco relativo;

$\alpha$ : Taxa do risco-país (Brasil) em relação aos EUA. 
Quadro 1. Empresas selecionadas.

\begin{tabular}{|c|}
\hline Empresas do Brasil \\
\hline $\begin{array}{l}\text { Petróleo Brasileiro S.A., Cyrela Brasil Realty S.A. Empreendimentos e Participações, Vale S.A, Centrais Elétricas } \\
\text { Brasileiras S.A., Telemar Norte Leste S.A, BRF Brasil Foods S.A., NET Serviços de Comunicação S.A., Lojas } \\
\text { Renner S.A, Cia. Siderurgia Nacional S.A., Centrais Elétricas de Santa Catarina S.A., Gerdau S.A, CCR S.A, Cia. } \\
\text { de Bebidas das Américas, Usinas Siderúrgicas de Minas Gerais S.A., Cia. Energética de Minas Gerais }\end{array}$ \\
\hline Empresas da Rússia \\
\hline $\begin{array}{l}\text { Gazprom OAO, Uralkali OJSC, Lukoil OAO, Severstal OAO, MMC Norilsk Nickel OJSC, Rushydro OJSC, } \\
\text { Rosneft Oil Co, Tatneft Surgutneftegas OJSC, Federal Grid Co., Unified Energy System JSC, Rostelecom OJSC, } \\
\text { Mobile Telesystems OJSC, Salavatnefteorgsintez JSC, Novolipetsk Steel OJSC, AK Transneft OAO }\end{array}$ \\
\hline Empresas da Índia \\
\hline $\begin{array}{l}\text { Reliance Industries Ltd., Bharti Airtel Ltd., Infosys Ltd., Steel Authority of India Ltd., Satyam Computer Services } \\
\text { Ltd., Bharat Heavy Electricals Ltd., Tata Steel Ltd., Maruti Suzuki India Ltd., Larsen \& Toubro Ltd., Tata } \\
\text { Consultancy Services Ltd., Tata Motors Ltd., ITC Ltd., Reliance Infrastructure Ltd., Wipro Ltd., Oil \& Natural Gas } \\
\text { Corp Ltd. }\end{array}$ \\
\hline Empresas da China \\
\hline $\begin{array}{l}\text { PetroChina Co Ltd., Sichuan Hongda Co. Ltd., China United Network Communications Ltd, China Shenhua } \\
\text { Energy Co. Ltd., China Vanke Co Ltd., China Telecom Corp. Ltd., China Petroleum \& Chemical Corp., Jiangxi } \\
\text { Copper Co. Ltd., Shanxi Xishan Coal \& Electricity Power Co. Ltd., Anhui Conch Cement Co. Ltd., Baoshan Iron } \\
\& \text { Steel Co. Ltd., China Yangtze Power Co. Ltd., Wuliangye Yibin Co. Ltd., Shandong Gold Mining Co. Ltd., Inner } \\
\text { Mongolia Baotou Steel Rare-Earth Hi-Tech Co. Ltd. }\end{array}$ \\
\hline Empresas dos EUA \\
\hline $\begin{array}{l}\text { Apple Inc., Oracle Corp., Microsoft Corp., Wal-Mart Stores Inc., Intel Corp., Johnson \& Johnson, Cisco Systems } \\
\text { Corp., Dell Inc., Exxon Mobil Corp., Amgen Inc., General Eletric Co., Chevron Corp., International Business } \\
\text { Machines Corp., The Procter \& Gamble Co., Pfizer Inc. }\end{array}$ \\
\hline Empresas do Japão \\
\hline $\begin{array}{l}\text { Kura Corp., Takeda Pharmaceutical Co. Ltd., Toyota Motor Corp., Toshiba Corp., Trans Genic Inc., Nissan Motor } \\
\text { Co. Ltd., Sony Corp., Nippon Telegraph \& Telephone Corp., NTT DoCoMo Inc., Panasonic Corp., Canon Inc., } \\
\text { KDDI Corp., Nippon Steel Corp., FANUC Corp., Honda Motor Co. Ltd. }\end{array}$ \\
\hline Empresas da Alemanha \\
\hline $\begin{array}{l}\text { Siemens AG, RWE AG, Deutsche Telekom AG, Bayerische Motoren Werke AG, Daimler AG, Infineon } \\
\text { Technologies AG, E. ON AG, ThyssenKrupp AG, SAP AG, Deutsche Post AG, Volkswagen AG, MAN SE, BASF } \\
\text { SE, Metro AG, Bayer AG }\end{array}$ \\
\hline
\end{tabular}

Nos cálculos, foram adotados betas setoriais não alavancados do mercado dos EUA. Os betas não alavancados foram ajustados pelo risco de cada empresa, tomando-se como referência o seu nível de endividamento. A Equação 5 foi aplicada:

$$
\beta_{L}=\beta_{U} *\left[1+\left(\frac{D}{E}\right) *(1-T)\right]
$$

Em que:

$\beta_{\mathrm{L}}$ : Coeficiente beta alavancado;

$\beta_{\mathrm{U}}$ : Coeficiente beta não alavancado do setor de atuação da empresa;

E: Capital próprio (Equity);

D: Capital oneroso de terceiros (Debt);

T: Alíquota do Imposto de Renda (Taxes).

Para o cálculo do custo do capital próprio, foi adotado como parâmetro para taxa livre de risco o retorno do título do governo americano T-bond de dez anos. O prêmio pelo risco de mercado foi obtido pela diferença entre taxa média de retorno da carteira de mercado das ações norte-americanas e a taxa livre de risco. A carteira de mercado foi representada pelo índice $S \& P 500$. O risco-país de cada um dos países considerados foi calculado pela diferença entre a remuneração paga pelos títulos públicos domésticos e pelo T-Bond do Tesouro dos EUA. Para o custo do capital de terceiros, foi adotada a taxa prime corporativa praticada no mercado de cada um dos países. Todos os dados foram obtidos em Damodaran Online (2011).

Uma vez obtidos os EVAs de cada empresa e para cada ano, foram obtidas as estatísticas descritivas (médias, desvios padrão, máximos, mínimos) das distribuições dos valores. Foram feitas as comparações das médias obtidas para cada grupo de países (desenvolvidos e BRIC), e também das médias das empresas dentro de cada grupo. As comparações foram feitas com base em testes de hipóteses. A principal hipótese testada, estabelecida como um par (hipótese nula e alternativa), é dada por:

$H_{0,1}$ : A média dos EVAs gerados pelas empresas dos países desenvolvidos é igual à média dos $E V A s$ gerados pelas empresas dos países do BRIC; 
$H_{1,1}$ : A média dos EVAs gerados pelas empresas dos países desenvolvidos não é igual à média dos EVAs gerados pelas empresas dos países do BRIC.

Para testar a normalidade das variáveis quantitativas, foi aplicado o Teste de Kolmogorov-Smirnov (KS). Como as amostras estudadas não respeitaram os pressupostos de normalidade, foi adotado o Teste não paramétrico de Mann-Whitney, análogo ao Teste $t$-student para amostras independentes, para verificar se duas amostras independentes provêm de duas populações com médias iguais, ao nível de significância estatística pré-estabelecido em 5\%.

Para comparar o desempenho das empresas e cada país, foi adotado o Teste não paramétrico de Kruskal-Wallis, que é usado para testar se três ou mais amostras independentes foram extraídas de populações com médias iguais. O Teste de Kruskal-Wallis pode ser usado com dados ordinais, intervalares, ou proporcionais sem a exigência de que as distribuições sejam normais e as variâncias homogêneas. Quando se detecta diferenças significativas de médias com este teste, usualmente são efetuadas comparações múltiplas envolvendo todos os pares, com o pós-teste de Dunn.

\section{Resultados}

Na Tabela 1, estão dispostas as estatísticas descritivas obtidas para a distribuição dos EVAs em cada grupo de países (desenvolvidos e BRIC).

Os dados da Tabela 1 mostram que a média anual de geração de valor obtida pelas empresas dos países desenvolvidos (US\$231.377.000), ao longo do período de onze anos, foi 2,9 vezes maior que aquela obtida pelas empresas dos países do BRIC (US\$79.764.000). $\mathrm{O}$ desvio padrão da distribuição de valores do $E V A$ para o grupo dos países desenvolvidos foi muito amplo e corresponde a 22 vezes o valor da média. O desvio padrão do grupo de países do BRIC também foi muito amplo, correspondendo a 19,6 vezes o valor médio do EVA anual.

A Tabela 2 mostra os resultados do Teste de Mann-Whitney. Os números mostram que os valores médios dos EVAs obtidos para cada um dos dois grupos de países não são iguais, sob um nível de 5\% de confiabilidade estatística.

Apesar do destaque no cenário mundial e das altas taxas de crescimento nos últimos anos, o conjunto de empresas dos países emergentes teve um desempenho inferior ao grupo das empresas dos países desenvolvidos, levando em consideração a geração de EVA. Os países do BRIC ainda não apresentam um ambiente aprimorado no que tange à existência de instituições confiáveis, à estabilidade econômica e política, e a outras estruturas como a fiscal e a de mercado. De acordo com Garelli (2006), as políticas implementadas pelos governos moldam o ambiente em torno das empresas, impactando de diversas formas o modo de operação de cada uma delas. Sendo assim, algumas nações propiciam melhores condições de competitividade às suas organizações do que outras, criando um ambiente favorável ao desenvolvimento e ajudando a estruturação de vantagens competitivas sustentáveis no longo prazo.

De forma geral, economias de mercados emergentes ainda apresentam características transitórias, fruto de um longo processo de mudança de mercados fechados para mercados com maior inserção global. Durante essa transformação, são normalmente implementadas reformas econômicas, políticas e sociais que conduzirão esses países a apresentarem uma performance mais consistente e duradoura, levando a maior transferência e eficiência ao sistema, mas como um lento processo até patamares mais próximos daqueles em que se situam os países desenvolvidos.

Segundo Shachmurove (2005), o BRIC ainda não pode ser categorizado como um grupo de países desenvolvidos. Algumas deficiências apontadas são a proteção aos direitos de propriedade, o acesso ao crédito, a baixa eficiência do sistema judiciário, a péssima política de arrecadação de impostos e a baixa qualidade dos serviços especializados. Estas deficiências constituem algumas barreiras prejudiciais ao crescimento e produtividade das empresas. Garg (2011) concorda, elencando alguns fatores necessários para a continuidade da trajetória de ascensão econômica no grupo de países emergentes. Entre eles estão a estabilidade macroeconômica, melhor funcionamento dos sistemas de saúde e de ensino, diminuição da burocracia, maior abertura ao comércio e ao investimento estrangeiro direto e educação e formação para criar uma força grande de trabalhadores qualificados.

Outra hipótese, que pode explicar a diferença observada nos níveis de geração de valor entre as firmas dos dois grupos de países, é baseada na ideia de que o sistema capitalista global é hierarquizado, trata de um sistema em que os países têm importância e influências distintas de acordo com suas dimensões econômica, territorial e populacional. Nos trabalhos de Arrighi (1995) e de Santos (2004), é demonstrada

Tabela 1. Estatísticas descritivas do EVA nos grupos de países.

\begin{tabular}{lccccc}
\hline \multicolumn{1}{c}{ Grupo de Países } & N & Média* & Desvio Padrão* & Mínimo* & Máximo* \\
\hline Desenvolvidos & 494 & 231.377 & 5.102 .260 & -29.482 .130 & 26.213 .597 \\
BRIC & 621 & 79.764 & 1.566 .850 & -9.799 .810 & 10.069 .844 \\
\hline
\end{tabular}

*[US\$ Milhares]. 
uma relação histórica orgânica entre estes grupos de países, isto é, uma relação pautada pela hegemonia dos desenvolvidos e dependência dos emergentes, com a tendência de persistir, a menos que haja algum tipo de alteração no cenário econômico mundial. Flemes (2010) concorda afirmando que a prosperidade econômica do BRIC está ligada às tendências cíclicas das economias dos países industrializados, visto que seus mercados internos não prosperam sem as exportações àqueles mercados. Então, por mais que as altas taxas de crescimento observadas no BRIC sejam um fenômeno positivo, ainda haverá uma disparidade entre as principais economias e os países em desenvolvimento.

Outro ponto importante a ser considerado na análise é a necessidade de investimento das empresas do BRIC. Por estarem em um momento de crescimento econômico, é possível que os gestores estejam com a necessidade de captar e investir um volume grande de recursos, para que no futuro a geração de fluxos de caixa seja positiva e mais expressiva. Este fato pode impactar o desempenho da análise do EVA nos onze anos estudados, considerando o prazo de maturação dos investimentos.

Nas Tabelas 3 e 4 são apresentadas, respectivamente, as estatísticas descritivas das distribuições dos valores do NOPAT e do ROIC obtidos em cada um dos dois grupos de países (desenvolvidos e BRIC). Os números mostram que o resultado operacional médio das empresas dos países desenvolvidos, medido pelo NOPAT, foi cerca de 2,7 vezes o valor obtido para o grupo de países do BRIC. Contudo, as taxas médias de retornos sobre o capital investido (ROIC) foram muito próximas: 19,15\% a.a. para os países desenvolvidos e 19,96\% a.a. para o BRIC. Não se pode explicar o melhor desempenho dos países desenvolvidos na geração de valor pelo retorno sobre

Tabela 2. Teste Mann-Whitney para o EVA nos grupos.

\begin{tabular}{lc}
\hline \multicolumn{1}{c}{ Estatística } & Valor \\
\hline Mann-Whitney $U$ & 138.146 \\
Wilcoxon $W$ & 331.277 \\
Z Statistic & $-2,853$ \\
Asymptotic Significance (2-tailed) & 0,004 \\
\hline
\end{tabular}

o capital investido. Por outro lado, considerados os resultados operacionais em termos absolutos, há uma grande lacuna entre as médias de NOPAT dos dois grupos. Esta diferença está relacionada ao tamanho das empresas, observado pelo faturamento e pelo volume de ativos. As empresas do BRIC têm, em geral, um porte menor quando comparadas às empresas do grupo de países desenvolvidos.

As Tabelas 5 e 6 mostram os resultados do Teste de Mann-Whitney aplicado para comparação dos valores médios do NOPAT e do ROIC, obtidos para cada um dos dois grupos de países, respectivamente. Os números mostram que ambos os valores médios, de $N O P A T$ e de $R O I C$, não são iguais entre os dois grupos de países, sob um nível de $5 \%$ de confiabilidade estatística.

De acordo com Almeida (2007), apesar de um bom número de empresas transnacionais (inclusive pequenas e médias) terem suas matrizes em países do BRIC, poucas são genuinamente globais quando comparadas com as organizações de países desenvolvidos. Além disso, poucas têm liderança industrial mundial, possuem marcas globais, gestão de classe mundial e modelos superiores de negócios.

As empresas dos países desenvolvidos conseguiram alcançar vantagens ligadas à economia de escala e de escopo, além de fortalecer suas posições comerciais e promover o crescimento de suas atividades operacionais. Vantagens como o acesso a fatores de produção e configuração internacional de suas operações; diversificação geográfica de seus mercados, diminuindo a dependência da demanda do país de origem; acesso a uma base ampla de recursos financeiros, o que contribui para maior competitividade financeira; também diminui o risco relativo a condições cíclicas (UNCTAD, 1995).

O último componente do $E V A$, que pode fornecer alguma informação acerca dos níveis de geração de valor, é o custo médio ponderado de capital das empresas. A Tabela 7 exibe as estatísticas descritivas obtidas para a distribuição das taxas médias ponderadas de custo de capital (WACC) das empresas de cada grupo de países (desenvolvidos e BRIC).

Os números da Tabela 7 revelam que a taxa média de custo de capital, medido pelo $W A C C$, a que se

Tabela 3. Estatísticas descritivas das distribuições dos valores de NOPAT.

\begin{tabular}{lccccc}
\hline \multicolumn{1}{c}{ Grupo de Países } & N & Média* $^{*}$ & Desvio Padrão* & Mínimo* & Máximo* \\
\hline Desenvolvidos & 494 & 4.943 .632 & 6.400 .290 & -16.857 .459 & 43.189 .423 \\
BRIC & 622 & 1.850 .184 & 3.911 .587 & -1.960 .409 & 33.950 .564 \\
\hline
\end{tabular}

*[US\$ Milhares].

Tabela 4. Estatísticas descritivas das distribuições dos valores do ROIC.

\begin{tabular}{lccccc}
\hline \multicolumn{1}{c}{ Grupo de Países } & N & Média* $^{*}$ & Desvio Padrão* & Mínimo* $^{*}$ & Máximo* $^{*}$ \\
\hline Desenvolvidos & 494 & 19,15 & 32,7 & -140 & 192 \\
BRIC & 622 & 19,96 & 18,7 & -37 & 137 \\
\hline
\end{tabular}

$*[\%$ ao ano $]$. 
submetem as empresas dos países do BRIC (14,14\% a.a.) é mais elevada do que a dos países desenvolvidos ( $11,31 \%$ a.a.). A diferença de $2,83 \%$ a.a. reflete um custo de capital nos países emergentes $25 \%$ maior do que o disponível nos países desenvolvidos.

A Tabela 8 mostra os resultados do Teste de Mann-Whitney aplicado sobre os valores do WACC. Os números revelam que os valores médios dos WACC obtidos para cada um dos dois grupos de países não são iguais, sob um nível de 5\% de confiabilidade estatística.

Um WACC mais elevado constitui uma dificuldade adicional para as empresas dos países emergentes. Para que consigam obter a geração de valor econômico adicional, suas operações devem atingir resultados mais expressivos, capazes de superar um custo de capital mais elevado.

O risco total de uma empresa tem forte ligação com o custo das suas alternativas de financiamento. Quanto maior o risco, maior é o retorno esperado pelos financiadores, elevando o custo de capital. As condições econômicas e políticas do ambiente em que a empresa opera também são fatores influentes na formação do custo de capital de uma empresa, tanto o capital próprio quanto o da dívida.

Por estarem no patamar de países emergentes, ainda que com algum destaque, apresentam riscos relacionados às incertezas dos acontecimentos nos âmbitos político, econômico e social. Alguns componentes deste risco que permeia o funcionamento das organizações, denominado risco-país, são: a potencialidade de surgimento de barreiras ao livre fluxo de capital, a

Tabela 5. Teste Mann-Whitney para comparação dos valores médios de NOPAT.

\begin{tabular}{lr}
\hline \multicolumn{1}{c}{ Estatística } & \multicolumn{1}{c}{ Valor } \\
\hline Mann-Whitney $U$ & 81.450 \\
Wilcoxon $W$ & 275.203 \\
Z Statistic & $-13,497$ \\
Asymptotic Significance (2-tailed) & 0,000 \\
\hline
\end{tabular}

Tabela 6. Teste Mann-Whitney para comparação dos valores médios de ROIC.

\begin{tabular}{lc}
\hline \multicolumn{1}{c}{ Estatística } & Valor \\
\hline Mann-Whitney $U$ & 129.976 \\
Wilcoxon $W$ & 252.241 \\
Z Statistic & $-4,424$ \\
Asymptotic Significance (2-tailed) & 0,000 \\
\hline
\end{tabular}

possibilidade de desvalorização da moeda, o risco de não pagamento de empréstimos internacionais e o risco derivado da inflação. Estes fatores amplificam o custo do capital e, consequentemente, prejudicam a capacidade de geração de valor das empresas do BRIC.

Na Tabela 9, estão dispostas as estatísticas descritivas dos valores de $E V A$ gerados pelas empresas de cada um dos países considerados neste estudo.

Os números da Tabela 9 mostram que as empresas dos EUA são as que, na média, mais geraram valor (US\$2.877.253.000/ano). As empresas japonesas, alemãs e brasileiras destruíram valor, na média. No agregado, os EUA são destacadamente o país cujas empresas mais geraram valor econômico aos seus acionistas (US\$475 trilhões). É nítida também a diferença de escala de valores entre os mercados desenvolvidos e os do BRIC. As empresas brasileiras destruíram, ao longo dos onze anos considerados no estudo, cerca de US\$1,1 bilhão.

O Teste de Kruskal-Wallis, cujos resultados estão apresentados na Tabela 10, comprovou a existência de diferenças estatisticamente significativas (nível de 5\%) entre os valores médios dos $E V A$ gerados em cada um dos países. O Teste de Dunn, cujos resultados constam da Tabela 11, ratificou a existência de diferenças significativas apenas entre os valores médios de $E V A$ dos EUA com relação aos demais países, e entre os da Índia e do Japão.

Ao se analisar o EVA e seus componentes nas empresas separadas por país, verificou-se que as empresas alemãs, em média, destruíram valor no período estudado, impactando negativamente o índice de geração de valor do grupo dos países desenvolvidos. Este desempenho ruim no indicador EVA pode ser explicado pela baixa rentabilidade sobre o capital investido de suas companhias, já que o custo médio ponderado de capital foi o menor encontrado em relação aos outros países da amostra. Apesar de a média do índice $R O I C$ superar a média do coeficiente $W A C C$, o resultado do $E V A$ foi negativo, isto devido ao fato de que as empresas destruidoras de valor tinham um montante de capital investido maior do que o investimento das companhias geradoras de valor, contribuindo com um peso negativo maior no resultado global no EVA do grupo de empresas alemãs.

As empresas brasileiras foram as únicas do grupo dos países emergentes a destruírem valor no período estudado, apresentando um $E V A$ agregado negativo. Analisando os componentes do EVA das companhias do Brasil, observa-se que a geração de resultado

Tabela 7. Estatísticas descritivas das distribuições dos valores do WACC.

\begin{tabular}{lccccc}
\hline Grupo de Países & N & Média* $^{*}$ & Desvio Padrão* & Mínimo* & Máximo* $^{*}$ \\
\hline Desenvolvidos & 494 & 11,31 & 3,54 & 4,0 & 25 \\
BRIC & 621 & 14,14 & 3,35 & 6,0 & 29 \\
\hline
\end{tabular}

*[\% ao ano $]$. 
operacional não é tão expressiva comparada com os demais países, mostrando uma necessidade de as empresas crescerem e ganharem escala aumentando suas estruturas produtivas. Apesar de não dispor de um montante de NOPAT comparável com as principais potencias e com a Rússia, as organizações brasileiras obtiveram o terceiro melhor posto no indicador de retorno sobre o capital investido, resultado capaz de superar a média do WACC. Esta relação positiva levaria à geração de valor, mas, assim como no caso da Alemanha, as empresas que mais tiveram uma parcela de contribuição no EVA agregado, observado nos níveis de capital investido, foram as destruidoras de valor.

Analisando as informações da China, constata-se que a média da geração de valor agregado das empresas foi positiva, indicando que foi adicionado valor no período de 2000 a 2010. Este bom resultado pode ser explicado pelo baixo custo médio ponderado de capital apurado nas companhias chinesas. Foi o menor do grupo dos países emergentes. A maioria das companhias conseguiu cobrir os custos de capital com seus resultados operacionais. Diante desta relação favorável, o resultado agregado do EVA poderia ser maior caso as organizações geradoras de valor aportassem um volume maior de capital e ampliassem suas atividades produtivas, mas mantendo a mesma rentabilidade.

Ao explorar as estatísticas das empresas norteamericanas, na média, houve forte geração de valor no período estudado. As empresas dos EUA foram responsáveis por todo o resultado positivo do EVA gerado no grupo dos países desenvolvidos, já que as empresas da Alemanha e do Japão destruíram valor no agregado. $\mathrm{O}$ resultado pode ser explicado

Tabela 8. Teste Mann-Whitney para comparação dos valores médios de $W A C C$.

\begin{tabular}{lr}
\hline \multicolumn{1}{c}{ Estatística } & \multicolumn{1}{c}{ Valor } \\
\hline Mann-Whitney $U$ & 79.824 \\
Wilcoxon $W$ & 202.089 \\
Z Statistic & $-13,772$ \\
Asymptotic Significance (2-tailed) & 0,000 \\
\hline
\end{tabular}

pela ótima rentabilidade sobre o capital investido das companhias dos EUA que supera o custo médio ponderado de capital, considerado alto quando comparado aos outros países industrializados. Cobrindo os custos de capital e alavancadas pelo elevado volume de recursos investido, as empresas dos EUA se destacaram com a melhor geração de valor entre as nações envolvidas no estudo.

As empresas japonesas foram observadas no estudo como as maiores destruidoras de valor, apresentando uma soma e uma média negativa no indicador $E V A$. $O$ resultado operacional demonstrou que o volume de dinheiro gerado pelas empresas japonesas é maior que o movimentado no grupo dos países emergentes, exceto a Rússia. Apesar disso, a gestão desse montante de capital operacional não foi eficiente já que o ROIC médio é muito baixo, ficando em $6,61 \%$. Este foi o principal fator responsável pelo péssimo resultado de valor das companhias japonesas. Na maioria dos casos, apesar de a média do $W A C C$ das organizações japonesas ter sido a segunda menor, a rentabilidade do capital investido não foi capaz de superar os custos exigidos pelos financiadores, reforçando o péssimo desempenho na rentabilidade obtido.

Ao analisar os resultados das empresas indianas, em média, ocorreu adição de valor no período estudado, impactando positivamente o grupo do BRIC. Na verdade, a Índia foi responsável pelo melhor resultado individual no indicador $E V A$ no grupo dos países emergentes. O bom desempenho alcançado colocou as companhias indianas no segundo posto de maiores geradoras de valor. Esta condição pode ser explicada pela maior rentabilidade sobre o capital investido das firmas indianas. O ROIC superou o custo médio ponderado de capital, observado como o maior comparado com os demais países do grupo. Analisando a equação, a eficiência na gestão proporcionou uma geração positiva de valor, no entanto este saldo positivo não foi alavancado por um grande volume de capital investido, o que poderia incrementar ainda mais a geração de riqueza calculada.

Finalmente, ao observar as informações das empresas russas, constata-se a média da geração de valor positiva, indicando que foi adicionado valor no

Tabela 9. Estatísticas descritivas das distribuições dos valores do EVA para cada país.

\begin{tabular}{lrrrrrr}
\hline \multicolumn{1}{c}{ Países } & N & Média* & \multicolumn{1}{c}{$\begin{array}{c}\text { Desvio } \\
\text { Padrão* }\end{array}$} & \multicolumn{1}{c}{ Soma* } & Mínimo* & Máximo* \\
\hline EUA & 165 & 2.877 .253 & 6.384 .347 & 475.000 .000 & -22.571 .162 & 26.213 .597 \\
Japão & 164 & -1.202 .851 & 3.285 .891 & -197.000 .000 & -26.003 .509 & 3.018 .018 \\
Alemanha & 165 & -988.963 & 4.020 .960 & -163.000 .000 & -29.482 .130 & 6.331 .118 \\
Brasil & 163 & -6.783 & 1.753 .487 & -1.105 .696 & -9.799 .810 & 6.859 .893 \\
Rússia & 143 & 46.836 & 1.820 .253 & 6.697 .598 & -6.515 .835 & 7.718 .189 \\
Índia & 159 & 142.588 & 702.674 & 22.671 .463 & -3.023 .560 & 3.197 .804 \\
China & 156 & 136.350 & 1.746 .882 & 21.270 .546 & -4.997 .808 & 10.069 .845 \\
\hline
\end{tabular}

*[US\$ Milhares]. 
Tabela 10. Teste Kruskal-Wallis para comparação dos valores médios de EVA.

\begin{tabular}{lc}
\hline \multicolumn{1}{c}{ Estatística } & Valor \\
\hline Chi-Square & 155.800 \\
Degree of freedon & 6 \\
Asymptotic Significance (2-tailed) & 0,000 \\
\hline
\end{tabular}

Tabela 11. Teste de Dunn para as diferenças dos valores médios de EVA.

\begin{tabular}{lrcccccc}
\hline & EUA & Japão & Alemanha & Brasil & Rússia & Índia & China \\
\hline EUA & & & & & & & \\
Japão & $401,7^{*}$ & & & & & & \\
Alemanha & $-327,8^{*}$ & 73,9 & & & & & \\
Brasil & $-311,5^{*}$ & 90,2 & $-16,3$ & & & \\
Rússia & $310,3^{*}$ & $-91,4$ & $-17,5$ & $-1,2$ & & \\
Índia & $254,4^{*}$ & $147,3^{*}$ & $-73,4$ & $-57,2$ & 56,0 & & \\
China & $-304,5^{*}$ & 97,2 & $-23,3$ & $-7,0$ & 5,8 & $-50,1$ & \\
\hline
\end{tabular}

*Significativos ao nível de 5\% de confiabilidade estatística.

período estudado. O resultado obtido pode ser explicado pela diferença positiva entre as médias do ROIC e do custo médio ponderado de capital, demonstrando uma rentabilidade das operações superior ao custo do capital utilizado. Este valor positivo de agregação de valor foi incrementado pelo fato de as organizações russas apresentarem uma boa capacidade de realizar investimentos com boa rentabilidade e pelo tamanho das operações das companhias russas, informação verificada na média do indicador NOPAT que foi o segundo melhor, perdendo apenas para os EUA.

\section{Conclusões e considerações finais}

A partir dos resultados deste trabalho, foi possível perceber que as empresas americanas se destacam na capacidade de geração de valor econômico, utilizando o EVA como parâmetro e em comparação com as empresas de todos os outros países analisados.

Ao considerarmos os dois grupos - desenvolvidos e emergentes - ambos agregaram valor ao capital dos acionistas na média dos 11 anos analisados, porém as empresas dos países desenvolvidos geraram três vezes mais valor que os países do BRIC. A participação dos EUA foi fundamental para este resultado já que as empresas da Alemanha e do Japão destruíram valor, se consideradas isoladamente.

Em relação aos resultados obtidos, podemos afirmar que, na média, as empresas dos países do BRIC agregam valor; que as taxas médias de retorno sobre o capital investido (ROIC) obtidas pelas empresas de ambos os grupos de países foram praticamente as mesmas, cerca de 19\% ao ano; que a taxa média ponderada de custo de capital das empresas do BRIC mostrou-se significativamente mais alta que a dos países desenvolvidos, cerca de $25 \%$ maior; e que a escala da geração de resultados operacionais e dos volumes de capital investido é significativamente menor nas empresas dos países do BRIC, quando comparada com a das empresas dos países desenvolvidos.

Duas das principais contribuições deste trabalho foram: i) mostrar que as empresas dos dois grupos de países possuem níveis médios de retorno sobre o capital investido praticamente iguais, apesar das diferenças das economias em que se inserem e do porte das empresas; ii) mostrar que três dos quatro países emergentes analisados apresentam um conjunto de empresas agregadoras de valor, enquanto que apenas um, dentre três países desenvolvidos, mostra esta característica.

Uma limitação deste trabalho foi não conseguir responder por que as empresas brasileiras destroem valor, enquanto empresas de países com características parecidas conseguem agregar. Como sugestão para estudos futuros e para sanar esta lacuna, recomenda-se a exploração de um método que investigue os aspectos ligados aos menores níveis de capital investido e aos custos, de várias naturezas, relativamente mais elevados aqui existentes.

\section{Referências}

Almeida, P. R. (2007). O Brasil como ator regional e como emergente global: estratégias de política externa e impacto na nova ordem internacional. Revista Cena Internacional, 9(1), 7-36.

Arrighi, G. (1995). A desigualdade mundial na distribuição de renda e o futuro do socialismo. In E.Sader. O mundo depois da queda. Rio de Janeiro: Paz e Terra.

Assaf, A., No. (2003). Finanças corporativas e valor. São Paulo: Atlas.

Copeland, T., Koller, T., \& Murrin, J. (2000). Avaliação de empresas: calculando e gerenciando o valor das empresas (2. ed.). São Paulo: Makron Books. 
Damodaran Online. (2011). New York. Recuperado em 5 de novembro de 2011, de http://pages.stern.nyu.edu/ adamodar/.

Dunbar, K. (2013). Economic value added: a thematic bibliography. Journal of New Business Ideas and Trends, 11(1), 54-66.

Ehrbar, A. (1999). EVA valor econômico agregado. Rio de Janeiro: Qualitymark.

Flemes, D. (2010). O Brasil na iniciativa BRIC: soft balancing numa ordem global em mudança? Revista Brasileira de Política Internacional, 53(1), 141-156. http://dx.doi.org/10.1590/S0034-73292010000100008.

Garelli, S. (2006). Competitiveness of nations: the fundamentals. In World Competitiveness Center - IMD. IMD World Competitiveness Yearbook. Switzerland.

Garg, R. (2011). BRIC: cooperation and competition in international relations. Hemispheres: the Tufts University. Journal of International Affairs, 34(1).

Ivanov, S. I., Leong, K., \& Zaima, J. K. (2014). An empirical examination of negative economic value added firms. The International Journal of Business and Finance Research, 8(1).

Mamun, A. A., Entebang, H., \& Mansor, S. A. (2012). EVA as superior performance measurement tool. Modern Economy, 3(3), 310-318. http://dx.doi.org/10.4236/ me.2012.33041.

Modigliani, F., \& Miller, M. H. (1963). Corporate income taxes and the cost of capital: a correction. The American Economic Review, 53(3), 433-443.
Modigliani, F., \& Miller, M. H. (1959). The cost of capital, corporation finance and the theory of investment [reply]. The American Economic Review, 49(4), 655-669.

Modigliani, F., \& Miller, M. H. (1958). The cost of capital, corporation finance and the theory of investment. The American Economic Review, 48(3), 261-297.

O'Neill, J. (2001). Building better global economic BRICs (Global Economics Paper, No. 66). Goldman Sachs.

Rappaport, A. (2001). Gerando valor para o acionista: um guia para administradores e investidores. São Paulo: Altas.

Santos, T. (2004). Economía mundial la integración latinoamericana. México: Plaza Janés.

Shachmurove, Y. (2005). Dynamic linkages among the emerging Middle Eastern and the United States stock markets. International Journal of Business, 10(1).

Sharpe, W. F. (1964). Capital asset prices: a theory of market equilibrium under conditions of risk. The Journal of Finance, 19(3), 425-442.

Sirbu, A. (2012). Economic Value Added (EVA) Approach in Russia. Concepts. Approaches. Instruments. Review of International Comparative Management, 13(2), 305-312.

Stewart, G. B. (1991). The quest for value. New York: HarperBusiness.

United Nations Conference on Trade and Development - UNCTAD. (1995). World investment report 1995: transnational corporations and competitiveness (ONU Reports, Vol. 95, No. 2). Geneva: UNCTAD. 